ването на проблемните хазартни игри като нарушение на психичното здраве, те рядко се разпознават като значим проблем на общественото здраве или като приоритет за превантивни и регулаторни усилия. Съществува спешна нужда хазартните игри да се разпознаят като приоритет от националните и международни програми за обществено здравеопазване и да се укрепят стратегиите, основаващи се на доказателства, и стратегиите за превенция, както и значително разширяване на ранната интервенция и предоставяне на лечение. Тези мерки са от решаващо значение за намаляване на настоящите и бъдещите щети и социални разходи, свързани с търговския хазарт. Предвид много високите нива̀ на вреда, свързана с хазарта, в някои групи от населението трябва да бъдат приложени целеви, както и по-универсални подходи, за да се намалят вредите и различията между различните социално-икономически и други социални групи [1]. Много от рисковете, които не са свързани с хазарта и защитните фактори за рисковия и проблемния хазарт, са често срещани при други заболявания на психичното здраве и пристрастеността. Намаляването на тези рискови фактори и засилването на защитните фактори може да се очаква да има здравни и социални ползи, които надхвърлят проблема с хазарта и свързаните с хазарта вреди.

По време на посещението в България на Генералния директор на С3О д-р Тедрос (2-4 март 2018 г.) бе определена необходимостта от техническа помощ от СЗО в областта на здравното осигуряване и подобряване на ефективността на финансирането на здравните услуги.
Правителството на България има за цел да подобри модела на грижа, като се занимава със здравното финансиране, включително плащанията извън джоба и НЗОК. След консултация и законодателен процес се очаква реформите да бъдат осъществени в началото на 2019 г.

Специално внимание е обърнато на важността на инвестирането в общественото здраве и в ориентиран към първичната помощ здравен модел.

\section{Библиография и референции}

1. Abbott, M. (2017b). Gambling and gambling harm in New Zealand: A 28 year case study. International Journal of Mental Health \& Addiction [Advance online publication] doi: 10.1007/s11469-017-9767-6.

2. WHO recommendations on antenatal care for a positive pregnancy experience 2016. www.who.int/reproductivehealth/publications/maternal_perinatal health/anc-positive-pregnancy-experience/en/

3. McDaid D, Sassi F and Merkur S (eds.) Promoting health, preventing disease: the economic case. Maidenhead, UK, 313-324. ISBN 978

4. Anderson and Baumberg (2010) reviewed cost-benefit analyses of alcohol policy and found no complete examples. They concluded that the Sheffield Alcohol Policy Model (SAPM) in England was the closest approach to a CBA (Purshouse et al. 2010). Anderson and Baumberg (2010) undertook their own CBA based on a hypothetical counterfactual of an increase in alcohol excise taxes that would result in an across-the-board 10 per cent increase in alcohol prices in England, with estimates of the impact of such a price increase obtained from the SAPM. 03352622675, pp. 3-18.

5. Изследване на честите психични разстройства (ЕПИБУЛ), Националния центьр за обществено здраве (НЦОЗА), Сп, за обществено здраве.

6. OECD Expenditure on prevention 2014

7. Stuckler D et al. BMJ2010;340:bmj.c3311

8. Двугодишното споразумение за сьтрудничество с М3 за 2018/19 г.

Автор

Доц. Михаил Околийски, експерт по обществено здраве, Офис на СЗО в България

\title{
ДОБАВКИТЕ В ХРАНАТА - ОЦЕНКА ЗА БЕЗОПАСНОСТ
}

\section{Р. Вачкова-Петрова}

$\prod_{\text {TИч }}$ обавките в храната са голяма група вещества от синтетичен или натурален произход, които се влагат целенасочено в храната по технологични съображения. В нашата страна е в сила Наредба № 4 от 3 февруари 2015 г. за изискванията към използването на добавки, издадена от министъра на здравеопазването. С тази наредба се определят изискванията към използване на добавки в храните в съответствие с разпоредбите на Регламент (ЕО) № 1333/2008 на Европейския парламент и на Съвета на Европа от 16 декември 2008 г. относно добавките в храните [3, 4]. Спецификациите на добавките в храните, свързани по-специално с произхода, с критериите за чистота и с всяка друга необходима информация, са посочени в Регламент (ЕС) № 231/2012 на Комисията от 9 март 2012 г. за определяне на спецификации на добавките в храните, включени в списьците в приложения II и III към Регламент (EO) № 1333/2008 на Европейския парламент и на Съвета [5].

Съгласно нашето и международното законодателство „добавките в храните са вещества от натурален или синтетичен произход, които обикновено не се използват самостоятелно като храна или като преобладаваша съставка при производството на храни, независимо от това дали имат хранителни свойства и които се добавят по технологични съображения към храната при производството, преработката, опаковането, транспорта или съхранението й и остават като нейна съставка, дори и в променена формa”. Добавките в храните трябва да се одобряват и използват само, ако изпълняват критериите, заложени в законодателството: 1. Добавката не трябва да бъде опасна за здравето на потребителя въз основа на оценка на наличните научни доказателства; 2. Добавката е технологически нужна като нейните свойства не могат да бъдат постигнати чрез други икономически или технологични, практически приложими средства; 3. Използването на добавката не води до заблуждаване на потребителя.

\section{Оценка за безопасност на добавките в храните}

Началото на научната оценка на използването на добавките в храните се поставя през 50-те години на XX век при съвместните действия на ФАО и СЗО и създаването на смесен експертен комитет ФАО/СЗО по хранителните добавки (Joint Expert Committee on Food Additives - JECFA). Също през 50-те години на миналия век подобен въпрос е повдигнат и в САЩ от Администрацията по храните и лекарствата и Комитета по опазване на храната на Националния изследователски съвет, което довежда до препоръки за оценка на безопасността на химическите вещества, използвани като хранителни добавки. За първи път се предлага да се използва 100-кратна граница на безопасност между максималната безопасна доза в дългосрочните изследвания върху животни и максималния прием на химическото вещество от общата диета на човека. На базата на този подход JECFA разработва концепцията за допустимата дневна доза (ДДД), т.е. количеството от веществото, изразено на килограм телесна маса, което може да бъде поемано ежедневно през иелия живот без доловим риск за здравето. Количеството се изразява по отношение на телесното тегло, за да се вземат 
предвид разликите в телесното тегло между опитните животни и човека и вариабилността в човешката популация (деца сравнени с възрастни). Отнася се за ежедневен прием, защото веществото не трябва да се натрупва в организма. ДДД може да бъде определена като приемът, за който се допуска, че е „без доловим риск” за здравето [17, 20, 21, 22].

Оценката за безопасност се извършва на европейско ниво от Европейския орган по безопасност на храните (EFSA) и неговия специализиран Панел по добавките в храните и хранителните източници, прибавяни в храната, а на глобално ниво - от специализирания комитет на ФАО/СЗО по хранителните добавки и замърсителите.

EFSA, основно чрез Панела, има три главни дейности, свързани с добавките:

1. Провежда оценка за безопасност на новите добавки в храните преди те да бъдат оторизирани за използване в $\mathrm{EC}$;

2. Отговаря на ad-hoc запитвания и изисквания от Европейската комисия за преразглеждане на някои добавки в светлината на значителна нова научна информация и/или променени условия за употреба;

3. Провежда системно преразглеждане на всички приети добавки в ЕC [12].

Така EFSA провежда „ревизия” на добавки, за които са се появили нови научни данни за евентуално въздействие върху организма както по искане на Комисията, така и по предварително разработен план, какъвто е случаят с оцветителите. Процесът на преоценка не приключва и не е свързан с нов списък на добавките, а по-скоро с промяна на статуса на отделни добавки.

Официалният списьк на добавките включва и техните Е номера. Е номерата са кодове за добавките в храните в Европейския съюз и означават, че съответните добавки са оценени за безопасност и одобрени за употреба. Схемата за номериране следва международната система за номериране International Numbering System (INS), определена от Комисията „Кодекс Алиментариус“. Класификацията по номера е следната:

1. Е100-Е199 (оцветители);

2. Е200-Е299 (консерванти);

3. E300-E399 (антиоксиданти, регулатори на киселинността);

4. Е400-Е499 (сгъстители, стабилизатори, емулгатори);

5. Е500-Е599 (регулатори на киселинността, антислепващи агенти);

6. Е600-Е699 (подобрители на вкуса);

7. Е700-Е799 (антибиотици);

8. Е900-Е999 (различни, главно подсладители);

9. Е1000-Е1999 (допълнителни химически вещества)

\section{Токсикологични изследвания}

Добавките се подлагат на токсикологична оценка с редица краткосрочни и дългосрочни изследвания върху експериментални животни (а в някои случаи и наблюдения върху хора), тестове in vitro. През 2009 г. Европейският орган по безопасност на храните публикува своите изисквания към досиетата за оценка на хранителните добавки [12]. Досиетата трябва да включват информация относно:

- Предложител и досие на предложителя (административни данни);

- Идентичност и характеризиране на добавката (включително предложените спецификации и аналитичен метод). Идентифицира добавката в храната, потенциалните опасности (онечиствания, остатъчни вещества) от нейното производство и чрез спецификацията идентифицира тестирания материал. Специални изисквания има за различните видове добавки: единична субстанции, прости смеси, комплексни смеси, които не са получени от ботанически източници; полимери, добавки от ботанически източници, наноматериали; материали, съдържащи микроорганизми или получени от микроорганизми $[13,14]$;

- Производствен процес;

- Стабилност, реакции и съдба на добавката в храните, за които е предназначена

- Необходимост от добавката и предлагани употреби.

Изискваните биологични и токсикологични данни при оценката за безопасност и формулирането на допустимата дневна доза на предлаганите добавки са от следните области:

- токсикокинетика;

- субхронична токсичност;

- генотоксичност;

- хронична токсичност/канцерогенност;

- токсичност върху репродукцията и развитието.

Добавките трябва да бъдат предмет на дългосрочно наблюдение и да бъдат преоценявани в светлината на променените условия за употреба или нова научна информация. Веществата, които са генотоксични и канцерогенни не могат да бъдат обсъждани за включване в тази широка група вещества [10].

През 2012 г. Панельт в своето упътване относно представянето на документи за оценка на добавките в храните описва парадигмата оценка на риска (включително идентификацията и характеристиката на опасността, оценка на експозицията и характеризиране на риска), които се използват при предприемането на оценката на риска [14]. За първи път се описва подход за ранкиране на токсикологичните изследвания - Таблица 1. Те са поставени в три реда, в които се описват изискванията за тестиране, ключовите въпроси и пусковите механизми. Според този подход в ред 1 се разработват минималните количества данни, приложими за всички вещества, докато ред 2 се изисква за вещества, които се абсорбират, демонстрират токсичност или генотоксичност в изследвания от ред 1 , за да се натрупат по екстензивни данни. Тестирането при ред 3 трябва да се провежда „случай по случай” като се вземат под внимание всички налични данни, за да се изяснят специфичните крайни резултати, които изискват по-нататъшно изследване. Подходът за подреждане на изследванията в редове се планира, за да се оценят следните същностни области: токсикокинетика, генотоксичност, токсичност (с насоченост към субхронична токсичност, хронична токсичност и канцерогенност) и токсичност върху репродукцията и развитието. Понякога са необходими и други изследвания за адекватна оценка на риска като например имунотоксичност, хиперчувствителност и хранителна непоносимост, изследване за невротоксичност, ендокринна токсичност и механизми и начин на действие. В обосновката на подхода е включена концепцията, че резултатите от изследванията при по-високия ред по принцип изместват резултатите от по-ниския ред. По-високото изследване може да се налага от резултатите в една от съществените области, напр. когато резултатите от абсорбцията или 90-дневния опит изискват по-нататьшни изследвания от ред 2 . Ако на ред 1 in vitro изследването за генотоксичност е отрицателно не би имало нужда от изследване на генотоксичността на ред 2.

Ранкиращият подход взема предвид благополучието на животните като приема стратегия за тестиране върху животни в съответствие с линията ,3-Rs" (replacement, refinement, reduction-заместване, усъвършенстване, редукция) [14]. 
Таблица 1. Ранкирано тестиране за токсичност при добавките в храните

\begin{tabular}{|c|c|c|}
\hline $\begin{array}{l}\text { Ред } 1 \\
\text { Абсорбция } \\
\text { Тестиране за геноток- } \\
\text { сичност } \\
\text { In vitro тестиране } \\
\text { Токсичност } \\
\text { Pазширен 90-дневен } \\
\text { oпит } \\
\text { Насочва и обосновава } \\
\text { обсъждане на стьпка } \\
2 \\
\text { с системна наличност } \\
\text { - генотоксичност с іn } \\
\text { vitro тест } \\
\text { Токсичност в 90-дневния } \\
\text { опит }\end{array}$ & $\begin{array}{l}\text { Ред } 2 \\
\text { ADME (АРМЕ)* } \\
\text { Единствена доза } \\
\text { Генотоксичност } \\
\text { In vivo тестиране } \\
\text { Токсичност (самодтоя- } \\
\text { телна или в комбина- } \\
\text { ция) } \\
\text { Хронична } \\
\text { Канцерогенност } \\
\text { Токсичност върху } \\
\text { репродукцията и } \\
\text { развитието } \\
\text { ЕОGRTS ** } \\
\text { Пренатална токсич- } \\
\text { ност върху развитието } \\
\text { Насочва и обосновава } \\
\text { обсъждане на стъпка } \\
\text { 3 } \\
\text { Биоакумулация } \\
\text { Положителна in vivо } \\
\text { генотоксичност } \\
\text { Хронична токсичност/ } \\
\text { канцерогенност } \\
\text { Токсичност върху репро- } \\
\text { дукцията и развитието }\end{array}$ & $\begin{array}{l}\text { Ред } 3 \\
\text { АDME* } \\
\text { Повтаряща се доза, из- } \\
\text { следване на доброволии } \\
\text { Канцерогенност } \\
\text { Начин на действие } \\
\text { Токсичност върху } \\
\text { репродукцията и } \\
\text { развитието } \\
\text { Специализирани } \\
\text { изследвания } \\
\text { Имунотоксичност } \\
\text { Невротоксичност } \\
\text { Ендокринна активност } \\
\text { Начин на действие }\end{array}$ \\
\hline
\end{tabular}

*ADME- absorption, distribution, metabolism, elimination (Абсорбция, разпространение, метаболизъм, елиминиране - APME)

**EOGRTS - Extended One-Generation ReproductionToxicity Study (Разширено токсикологично изследване на репродукцията върху едно поколение)

\section{Парадигмата оценка на риска Идентификация и характеристика на опасността}

По принцип се идентифицира най-чувствителният краен резултат от поредица токсикологични опасности и тяхната зависимост доза-ефект. Той се приема за критичен ефект и се използва като база за оценка на риска. Определя се най-високата доза, при която този ефект не се наблюдава т.е. максималната недействаща доза (No Observed Adverse Effect Level - NOAEL), за да се определи така наречената peферентна точка или „отправна точка” (Point of Departure” (POD). Типично, отправната точка включва нивото без наблюдаван неблагоприятен ефект (NOAEL) или стойността BMDL (по-ниската доверителна граница на бенчмарк дозата (BMD). Научният комитет на EFSA напоследък подкрепи процедурата по бенчмарк дозата като предпочитан подход,за да се определи отправната точка (POD) $[10,11]$. Тя се дели на фактора за безопасност, чрез което се вземат под внимание токсикинетични и токсикодинамичните разлики между индивидите в човешката популация и животинските видове. При провеждането на оценката стремежът е към определянето на базирана на здравето ръководна стойност или допустима дневна доза приложима за цялото население $[17,18]$. ДДД се определя за вещества, за които е демонстрирана или се предполага праговост на токсичните механизми. Тя не се отнася за кърмачетата под възраст 12 месеца. Използването на добавки за формулите за малки деца са специален случай, за който са дадени специални препорьки от Смесения комитет ФАО/СЗО за хранителните добавки [20, 21, 22]. Същите препорьки са дадени от Научния комитет за храните на ЕС [23, 24]. Панельт на EFSA подкрепя тези препорьки [14].

ДЛ се движи от 0 до горната граница, което се приема като зона на приемливост на веществото. Тази мярка се предприема от комитетите ФАО/СЗО и ЕС, за да се стимулира използването на веществата в най-ниските нива̀, които са технологически подходящи (добра производствена практика - ДПП). Основните механизми за спазване на ДДД на съответната добавка са регламентираните в законодателството максимални нива̀ на употреба и видовете хранителни продукти, за които тя е разрешена.

В някои случаи не се налага изразяването на ДДД в числова форма. В тези случаи се използва терминът „ДДД неопределена". Това означава, че на базата на наличните данни (химически, биохимични, токсикологични и други), общият дневен прием на веществото, който възниква от употребата му в технологичните норми и от неговата евентуална предварителна наличност в храната, не носи опасност за здравето. Тези добавки се използват на принципа „колкото е необходимо" - КН (quantum satis) в съответствие с ДПП $[17,20,21,22]$.

За вещества, които имат (или се предполага да имат) общ механизъм на действие, може да се установи групова ДДД, която се отнася за всеки представител на групата или за цялата група. Панелът не установява временна ДДД за нова добавка, за да разреши употребата ѝ, докато се попълнят данните, но може да я използва при преоценка на добавката, която насочва към необходимостта от допълнителни данни.

При оценка на риска може да се определи и химически специфичния фактор на коригиране (chemical-specific adjustment factors (CSAFs). Този фактор е модифициран произволен фактор 10 за безопасност, който включва подходящи данни за видовите разлики или човешката вариабилност или в токсикокинетиката, или в токсикодинамиката [7, 9, 19, 23].

В случай, когато наличните данни за добавката, която не е нито генотоксична или генотоксична и канцерогенна са с известни недостатъци, Панельт използва подхода граница на безопасност (Margin of Safety (MOS) е отношение POD за критичния ефект към теоретичната, предсказана или оценена доза или концентрация на експозиция, като за целите на оценката на риска този термин се използва за вещества, които не са генотоксични при подхода за праговост), за да заключи дали би имало риск от предлаганата употреба или нива̀ на употреба $[10,15,18]$.

За вещества, за които не се предполага безопасно ниво на употреба като например генотоксичните канцерогени, не може да се установи ДДД. При оценката на риска от замърсители или остатъчни вещества в добавката, които са генотоксични и канцерогенни, Панельт използва подходът граница на експозиция (Margin of Exposure (MOE) е отношение POD за критичния ефект към теоретичната, предсказана или оценена доза или концентрация на експозиция, като за целите на оценката на риска този термин се използва на вещества, които са генотоксични и канцерогенни за сравняване на експозцията с бенчмарк дозата) $[10,15,18]$. Трябва да се установяват колкото е възможно по-ниски нива̀ на съдържание, отразени в спецификацията на продукта. Всяка предложена спецификация с данни за съдържание на неотстраними генотоксични и канцерогенни онечиствания трябва да е свързана с MOE поне 10000. При онечиствания, за които няма данни за канцерогенност може да се използва подходът ТТС за генотоксични вещества в размер на $0.15 \mu \mathrm{g} /$ човек/ден [16].

\section{Оценка на експозицията}

Уравнението за острата и хроничната експозиция с храната е следното:

Експозиция с храната $=(($ кониентрация на веществото 6 храната) х (хранителната консумация)) / телесното тегло в $\kappa 2$

Фундаменталната връзка между токсичността, която е присъща на дадено вещество и експозицията на населението 
образува основата за оценката на риска от потенциално опасните вещества. Оценката на експозицията е съществен елемент за количествената оценка на риска и за определянето на това дали веществото носи неприемлив риск за общественото здраве. Оценката на експозицията играе централна роля в работата на международните комитети $\Phi А О / С 3 О$ и EFSA. Оценката на експозицията като стъпка в научната оценка на риска е основата за изграждането на стандарти, указания и други препоръки. Това дава сигурност, че изискванията за безопасност на храните предпазват човешкото здраве, съгласувани са между отделните страни и са подходящи за международната търговия.

Целта е да се докаже, че безопасните нива̀ (напр. ДДД) не се превишават от консуматорите, включително от високите такива. Препоръчва се стъпаловиден подход като се започва със скрининг методите. Те надценяват експозицията на високите консуматори като използват консервативни предпоставки по отношение на хранителната консумация и химическата концентрация. По този начин се избягва погрешния извод за липса на опасност т.е. че експозицията е под ДДД и че не е необходима по-нататъшна по-точна оценка на експозицията $[8,12,14,17,27]$.

У нас има известен опит в тази област. Проведено е изследване за оценка на реалното постьпление на добавките в храната у българския консуматор чрез анкетния метод с разработване на въпросници, отправени към всички клонове на хранителната промишленост [1]. Изчислено е средното годишно и дневно per capita постъпление на отделните добавки: консерванти - бензоена, сорбинова, аскорбинова киселини; синтетични подсладители, натурални и синтетични оцветители, органични киселини, соли, нитрати, нитрити, полифосфати, ароматизанти, емулгатори, желиращи веществал. Приемът на добавки не надвишава подбраните ДДД (които са най-ниските в съответната функционална група) както за средния консуматор, така и за „екстремния” консуматор (95-и персентил) т.е. няма риск за здравето от употребата на разрешените в страната добавки в храната. През 2009 г. е определен теоретичният максимален дневен прием (ТМДП) на азо-оцветителите Тартразин, Сънсет жълто, Азорубин, Понсо $4 \mathrm{R}$ и Алура червено у българския консуматор [2]. ТМДП се изчислява като се умножи средната дневна per capita консумация на всеки хранителен продукт или група храни по официалното максимално ниво на употреба на добавката [8]. Използвани са данните за потреблението на основни хранителни продукти (средно на лице) на Националния статистически институт за 2008 г. Данните са за максималните нива̀ на употреба на оцветителите, регламентирани с действащата към момента наредба. Изчислението е за български консуматор със средно телесно тегло 60 кг. Резултатите показват, че средният дневен прием на азо-оцветителите за българския консуматор е значително по-нисък от съответната ДДД на оцветителя [2].

С влизането си в Европейския съюз ние се присъединяваме към неговите подходи за оценка на експозицията. Препорьчва се в рамките на Европейския съюз и страните членки тя да се извършва по определен модел [6]. Типично, данните за актуалната консумация на храни от националните и международните изследвания в Европа се комбинират с нива̀та на очакваната употреба на добавката, за да се оцени експозицията. Експозицията на добавката се определя чрез сумиране на съдържанието ѝ във всяка храна, в която се очаква нейното наличие. Това от своя страна се постига чрез умножаване на концентрацията на добавката в дадена храна или хранителна категория и консумацията на тази храна или хранителна категория. Концентрацията на хранителни добавки се получава от нива̀та на предлаганата употреба или максималните допустими нива̀, заложени в законодателството и ако е подходящо - от нормалната употреба, определена аналитично или декларирана от индустрията. Този резултат се разделя на съответното телесно тегло на индивидите в рамките на популацията, която е засегната, за да се определи експозицията, изразена на $\mathrm{kg}$ телесно тегло на ден.Тази оценка може да се извършва във връзка с въвеждането на нова добавки или модифицирането на нейната употреба, но може да бъде и важна профилактична мярка.

В заключение трябва да се подчертае значителната роля на Световната здравна организация и Европейския съюз в осигуряването на безопасната употреба на добавките в храните. Нашето законодателство е част от европейското законодателство. Оценката на експозицията и оценката на риска могат да бъдат проведени за вещества преди тяхното одобрение за използване (пред-регулационно или пред-маркетингово), или след тяхното одобрение и пускане на пазара (пост-регулационен или пост-маркетингов контрол). Оценката на експозицята в храната може да обхваща цялото население, както и критичните групи, които са чувствителни или се очаква да имат значително различна експозиция в сравнение с тази на общото население. Контролът трябва да бъде насочен към спазване на изискванията на действащата в страната наредба относно видовете разрешени добавки и нива̀та на тяхната употреба. Съществена профилактична мярка е оценка на експозицията на приоритетни добавки в специфични групи от населението - малки деца, деца, юноши, възрастни и стари хора. Тя показва истинското състояние на проблема за безопасността на разрешените за употреба добавки.

\section{Библиография}

1. Вачкова Р., Г. Милев, Л. Василева, М. Ставрева. Оценка на реалното постъпление на хранителни добавки у българския консуматор, Проблеми на храненето, том II, 1991

2. Вачкова-Петрова Р. Оценка за безопасност на азо оцветителите за храни, разрешени за употреба в EC, National Focal Point of EFSA, София, 2009

3. Наредба № 4 от 3 февруари 2015 за изискванията към използването на добавките в храните, ДВ. бр.12 от 13 февруари 2015, изм. и доп. ДВ.бр.11 от 2 февруари 2018

4. Регламент (ЕО) № 133382008 на Европейския парламент и на Съвета от 16 декември 2008 г. относно добавките в храните, OB L 354, 31.12.2008 г., стр. 16

5. Регламент (ЕС) 231/2012 на Комисията от 9 март 2012 за определяне на спецификации на добавките в храните, включени в списъците в приложения II и III към регламент No 1333/2008 на Европейския парламент и на Съвета, OBL 83, 22.3.2012 г.,стр.1

6. Arcella D.Food additive Intake Model (FAIM) template. Food additives reevaluation workshop. Parma, November 2017.

7. Bokkers, BGH, Slob W. Deriving a data-based interspecies assessment factor using the NOAEL and the benchmark dose approach. Critical Reviews in Toxicology 2007,37, 355-373.

8. Codex Alimentarius Commission.Guidlines for simple evaluation of food additive intake, CAC/GL 03-1989

9. Dorne JMC, Renwick AG,. The refinement of uncertainty/safety factors in risk assessment by the incorporation of data on toxicokinetic variability in humans. Toxicological Sciences 2005,86, 20-26.

10. EFSA. Opinion of the Scientific Committee on a request from EFSA related to a harmonised approach for risk assessment of substances which are both genotoxic and carcinogenic. EFSA Journal 2005, 282, 1-3

11. EFSA. Guidance of the Scientific Committee on a request from EFSA on the use of the benchmark dose approach in risk assessment. The EFSA Journal, 2009,1150, 1-72. 1

12. EFSA. Data requirements for the evaluation of food additive applications. Scientific Statement of the Panel on Food Additives and Nutrient Sources added to Food, The EFSA Journal 2009, 1188, 1-7

13. EFSA. Guidance on Safety assessment of botanicals and botanical preparations intended for use as ingredients in food supplements. EFSA Journal 2009, 1249, 1-19.

14. EFSA.Guidance for submission for food additive evaluations. EFSA Pane on Food Additives and Nutrient Sources added to Food (ANS)2, 3 European Food Safety Authority (EFSA), EFSA Journal 2012;10(7):2760 
15. EFSA, 2012. Statement on the applicability of the Margin of Exposure approach for the safety assessment of impurities which are both genotoxic and carcinogenic in substances added to food/feed. EFSA Journal 2012a, $10(3): 2578$

16. EFSA. Exploring options for providing preliminary advice about possible human health risks based on the concept of threshold of toxicological concern (TTC). EFSA Journal 2012;10(7):2750

17. IPCS.Environmental Health Criteria 70.Principles for the Safety Assessment of Food Additives and Contaminants in Food, WHO, Geneva,1987,

18. IPCS. IPCS Risk Assessment Terminology (Part 1: IPCS/OECD Key Generic terms used in Chemical Hazard/Risk Assessment, 2004

19. IPCS. Chemical-specific adjustment factors for interspecies differences and human variability:Guidance document for use of data in dose/concentration response assessment (Harmonization Project Document №2), 2005

20. JECFA.WHO Technical Report Series.General Principles Governing the Use of Food Additives, First Report of the Joint FAO/WHO Expert Committee on Food Additives. 129, WHO,Geneva, 1957
21. JECFA. WHO Technical Report Series, Evaluation of certain food additives and thecontaminants mercury, lead, and cadmium. Sixteenth report of the Joint FAO/WHO Expert Committee on Food Additives. №505, 1972

22. JECFA. Evaluation of certain food additives. 21 report of the Joint FAO/ WHO Expert Committee on Food Additives. №617, Geneva, 1978

23. Naumann BD, Silverman KC, Dixit R, Faria EC, Sargent EV. Case studies of categorical dataderived adjustment factors. Human and Ecological Risk Assessment 7, 61-105,2001.

24. SCF. Opinion on additives in nutrient preparations for use in infant formulae, follow-on formulae and weaning foods. 7 June 1996

25. SCF. Opinion of the Scientific Committee of Food on the applicability of the ADI (Acceptable Daily Intake) for food additives to infants. 1998.

26. WHO. Chemical-specific adjastment factors for interspecies differences and human varability:guidance document for use of data in dose/concentration respnse assessment,Geneva,2005

27. WHO, Environmental Health Criteria 240. Principles and Method for the Risk Assessment of Chemicals in Food, Geneva, 2009

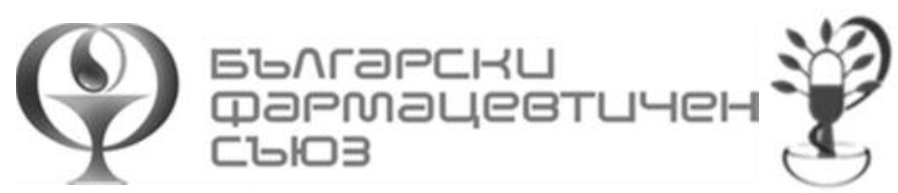

СДРУЖЕНИЕ ЗА ОНКОЛОГИЧНА ФАРМАЦИЯ
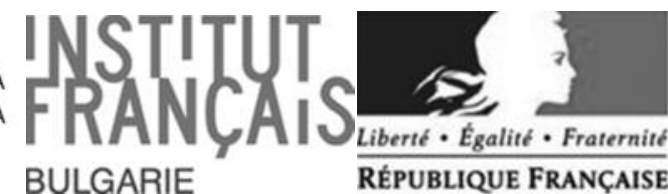
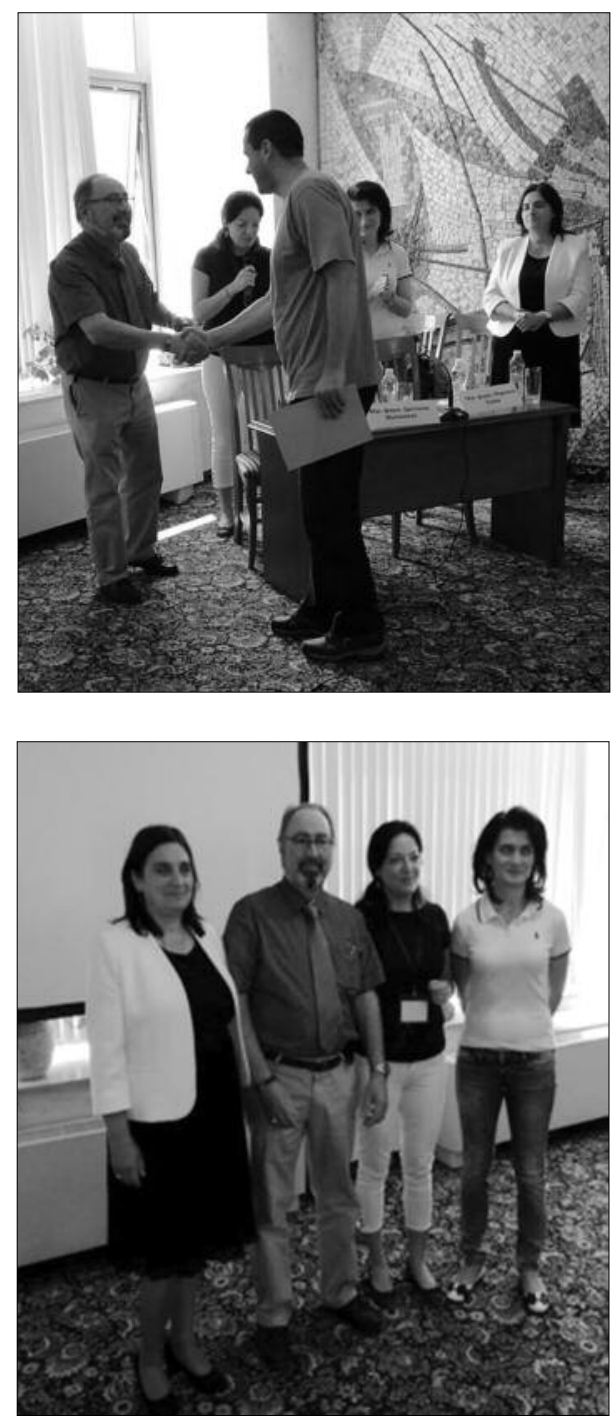

ЗА ВТОРИ ПЪТ В БЬЛГАРИЯ СЕ ПРОВЕДЕ ОСНОВЕН МАСТЬР КЛАС ПО ОНКОЛОГИЧНА ФАРМАЦИЯ, ОРГАНИЗИРАН ОТ БЪЛГАРСКИЯ ФАРМАЦЕВТИЧЕН СЬЮЗ (БФС) И БЪЛГАРСКОТО СДРУЖЕНИЕ ЗА ОНКОЛОГИЧНА ФАРМАЦИЯ (БСОФ)

Обучението се проведе като съпътстващо събитие в рамките на Българските фармацевтични дни 2018 г. Тридневният курс даде базови знания и умения, свързани с лекарствените продукти за системно лечение на злокачествени заболявания - механизъм на действие, начин на приготвяне, устройство и оборудване на помещенията за разтваряне на цитостатици. Разгледани бяха и личните предпазни средства, които трябва да се използват от персонала при работа с цитостатици. Обучението се основава на Стандарт за качество в областта на онкологичната фармация (QUAPOS), разработен и утвърден от Еuropean Society of Oncology Pharmacy (ESOP) и Правилата за добра фармацевтична практика и се проведе от лектори от България и ESOP от Франция и Турция.

В курса участваха основно магистър-фармацевти и помощник-фармацевти, които практикуват в лечебни заведения за болнична помощ, където се провежда лечение на пациенти с онкологични и злокачествени хематологични заболявания.

Лекциите бяха изнесени от:

Проф. Ален Астие - водещ лектор от Франция, заместник-председател на ESOP за периода 2016 - 2019 г., професор по клинична фармакология и биофармация, ръководител на катедра „Фармация” в университетска болница „Анри Мондор”, Париж, Франция.

Маг.-фарм. Ахмет Боснак, дф - лектор от Република Турция, заместникпредседател на ESOP за периода 2016 - 2019 г.

Маг.-фарм. Велина Григорова - лектор от България, комисар на ESOP в Европейската агенция за лекарствата, Председател на Професионалната организация на болничните фармацевти в България и член на УС на БФС.

Маг.-фарм. Мариана Енева - лектор от България, ръководител на болничната аптека при МБАЛ „Надежда“, гр. София.

Всички участници завършиха успешно курса и получиха сертификат от БФС и ЕSOP.

Проведеният Мастьр клас по онкологична фармация беше подкрепен с грант от Френския институт в България. 